\title{
Characterization of Temporal Trends of Dengue Fever in Municipalities in the Brazilian Northeast Outback
}

\author{
Emery Ciana Figueiredo Vidal ${ }^{1,2,3}$, Fernando Adami ${ }^{1}$, \\ Francisco Winter dos Santos Figueiredo ${ }^{1}$, \\ Luiz Carlos de Abreu ${ }^{1}$, Antonio Germane Alves Pinto ${ }^{2}$, \\ Eglidia Carla Figueiredo Vidal ${ }^{2,4}$, \\ Fernando Luiz Affonso Fonseca ${ }^{1,5}$
}

\section{Abstract}

Introduction: Dengue fever is currently a major endemic health issue in the city of Brejo Santo, located in the Brazilian Northeast outback, due to the rising morbidity and mortality rates in the area. The mosquito Aedes aegypti, the main vector of dengue fever virus, is highly adapted to the domestic environment. Since 1981 Brazil has been living with epidemic outbreaks of dengue fever.

Objective: To explain temporal trends of dengue fever in the municipalities of the $19^{\text {th }}$ Health Region of Brejo Santo within the years 2007-2013.

Methods: This is an observational, cross-sectional, descriptive study with a quantitative approach. Data were supplied by the Information System for Notifiable Diseases (SINAN) and the Mortality Information System (SIM). All notifications of dengue fever cases in the $19^{\text {th }}$ Health Region of Brejo Santo between January 2007 and December 2013 were included.

Results: A total of 7,766 cases of dengue fever were confirmed in the period between 2007-2013, among which 5 evolved to death. A high incidence was observed in most municipalities of the $19^{\text {th }}$ Health Region. A fluctuation in incidence could be observed with interspersing periods of large epidemic outbreaks. Most of these municipalities are at risk of dengue fever epidemics. The incidence in this region was of 378.1 cases per 10,000 inhabitants, and in the municipalities it ranged from 43.8 cases/10,000 inhabitants to 695.8 cases/10,000
1 Faculdade de Medicina do ABC (FMABC), Santo André, SP, Brazil.

2 Universidade Regional do Cariri (URCA), Crato, CE, Brazil.

3 Secretaria Estadual da Saúde do Ceará (SESA-CE), CE, Brazil.

4 Universidade Federal do Ceará, CE, Brazil.

5 Universidade Federal de São Paulo, Diadema, SP, Brazil.

\section{Contact information:}

Fernando Luiz Affonso Fonseca.

”profferfonseca@gmail.com 
inhabitants. Deaths by dengue fever were classified as: Dengue Fever with Complications (03); Dengue Shock Syndrome (01); Dengue Hemorrhagic Fever (01).

Conclusion: According to the information provided in this study, the greatest challenges health professionals have to face include the control of dengue fever and the prevention of death cases in the Health Region. To achieve good results, it is necessary to involve people in the process of co-responsibility, to strengthen links with other sectors of society, to promote adequate and timely assistance to the population and to improve the flow of health information, thus generating proactive and effective actions.

\section{Keywords}

Dengue Fever. Epidemiology. Incidence. Mortality.

\section{Introduction}

Dengue Fever is currently a major endemic health issue owing to the fact that many individuals get sick or are under the risk of getting sick. It is the most important emergent disease transmitted by arthropods that affect human beings due to the rising morbidity and mortality rates. The outbreak of emergent diseases can be set off by demographic, ecological and environmental factors given the closer contact of the vector and the virus with humans [1]. The main vector, the mosquito Aedes aegypti, which is highly adapted to the domestic environment, has found in the modern world suitable conditions for rapid proliferation. The accelerated urbanization generated issues like the lack of urban sanitation and water supply deficiency in large cities. Moreover, the intensive use of nonbiodegradable materials like disposable glass and plastic containers, along with climate changes, favor the mosquito range expansion [2].

Since 1981 Brazil has been living with epidemics of dengue fever. The mosquito Aedes aegypti is present nearly all over the country, coexisting with populations who are at risk to develop the disease in its most severe and hemorrhagic forms [3].
According to Braga and Valle [4], demographic changes, the intense migration flow, the disorderly growth of cities and poor sanitation conditions, with a resultant proliferation of Aedes aegypti, are factors that have contributed to the re-emergence of classic dengue epidemics and the emergence of dengue hemorrhagic fever (DHF).

The etiological agent of dengue fever is an arbovirus, a term used to refer to a group of viruses that are transmitted by arthropod vectors, of the gender Flavivirus, family Flaviviridae. It is classified into 4 serotypes, namely DEN-1, DEN-2, DEN-3 and DEN-4. Nevertheless, a recent research has identified DEN-5 serotype in blood samples from the 2007 dengue epidemic in Asia [5]. Regarding immunity, infection by one of the serotypes provides lifelong, or at least long-lasting, protection against that specific serotype. There is still the possibility of transient cross immunity among the 4 serotypes [6].

The Brazilian Ministry of Health defines dengue fever as a disease with a wide clinical spectrum which encompasses conditions from oligosymptomatic forms to extremely severe cases that may evolve to death. Within the latter, dengue hemorrhagic fever, hepatitis, hepatic insufficiency, nervous 
system manifestations, myocarditis, severe hemorrhage and shock are some of the highlighted consequent complications [7]. It is important to bring into the spotlight dengue clinical manifestations in children since they may not be noticed in the very beginning; the most severe conditions may be identified as the first clinical manifestations and, unlike in adults, disease aggravation in children is rapid.

Given the difficulty to diagnose the established epidemiological situation over the past few years, the State Health Secretary of Ceará issued a technical note recommending that all virus diseases be treated as dengue fever for the sake of preventive measures and medical assistance improvement. Also, in the technical note \# 023/2007, The Ministry of Health shows the increase of dengue hemorrhagic fever cases in children as well as the Brazilian states where the incidence is higher among this age group. The state of Ceará is among the states in which a great number of kids below 10 years of age and some below 1 year developed the disease [8].

Until the year 2013 dengue fever was classified as Classic (CD), Dengue Hemorrhagic Fever (DHF) or Dengue with Complications (DWC) [7]. In 2014 Brazil adopted a new classification scheme according to the World Health Organization (WHO) guidelines. Cases are now classified as dengue fever, dengue with warning signs and severe dengue [9].

So far no vaccine has been developed to prevent the disease; therefore, the main form of control has been through anti-vectorial measures, in practice since 2001, which replaced the previous eradication methods established in 1996. From then on, the Plan of Actions Intensification for Dengue Control (PIACD) has been implemented, prioritizing actions in those municipalities -named "priority municipalities"- where transmission is more intense. In 2002 the National Dengue Control Program (PNCD) was implemented with the aim to reduce the infestation of the Aedes aegypti, thus cutting down the incidence of dengue fever and lethal outcomes from dengue hemorrhagic fever [2].
Today dengue fever control is attempted by investments on methodologies that make the general population aware of the importance of behavior changes for a better environmental management, focusing on the rational use of insecticides and ensuring the effectiveness of actions with a resultant better vector control [4].

Dengue cases in the Americas have been reported for over 200 years, but it was only first described in the Philippines and in Thailand in the 1950s. From 1980 on, epidemics have been notified in many countries: Brazil (1982/1986-2002), Bolivia (1987), Paraguay (1988), Ecuador (1988), Peru (1990) and Cuba (1977/1981). In the latter country, cases of dengue hemorrhagic fever, associated to DEN-2, were notified in the year 1981, representing a milestone in the history of dengue fever in the Americas [2].

For around 60 years, between the years 1923 and 1982 to be exact, there were no records of dengue cases in Brazil. The Aedes aegypti was reintroduced in 1976, identified in Salvador, Bahia, and in many neighboring countries. With the epidemic in the state of Rio de Janeiro in 1986, dengue fever has taken on a whole new epidemiological importance. After this outbreak, other episodes occurred in the northeast region, thus turning dengue into an endemic disease in the country. Since then, alternate epidemic scenarios have been detected, always with the circulation of new serotypes. In the year 2002 approximately 800 thousand cases of dengue were reported, with 150 deaths by DHF, representing $80 \%$ of all cases in the Americas [10].

According to the information provided by the Ceará State Health Secretary (SESA/CE), there have been reports of dengue cases since 1986, the year when DEN-1 was isolated, with six major epidemics in the following years: 1987, 1994, 2001, 2008, 2011 and 2012. Special attention is called to the 1994 epidemic outbreak, due to the confirmation of the first hemorrhagic cases, to the 2008 outbreak, because of the high number of severe ca- 
ses of DHF and DWC, and to the 2011 epidemic, owing to the highest number of classic cases ever confirmed in the area. In 1994 the main factor for the onset of the first hemorrhagic cases was the circulation of the serotype DEN-2. Serotype DEN-3 was isolated in the year 2002 and DEN-4 in the year 2011 [11].

In the last 10 years dengue fever cases were reported in every month of each year, with an increase in rate in the first semester, maybe due to factors like the rise in rainfall, temperature and humidity. With the spread of DEN-4, the risk of severe cases will significantly increase since there will be the simultaneous circulation of the four serotypes, and most part of the municipalities is infested with the vector [11].

\section{The $19^{\text {th }}$ Health Region of Brejo Santo}

The Health Region of Brejo Santo is composed of the following municipalities: Abaiara, Aurora, Barro, Brejo Santo, Jati, Mauriti, Milagres, Penaforte and Porteiras. Brejo Santo is the largest municipality of the area, with the best resolution skills in many Medium and High Complexity Services (MACS); therefore, it is a provider of health services support to the other municipalities.

In the terms of Decree \# 7508/11, a Health Region is defined as a continuous geographic space composed of a cluster of bordering municipalities, outlined according to cultural, economic and social identities, with shared communication network and transportation infrastructure which aim to integrate the organization, the planning and the execution of actions and health services [12].

Figure 1: Location and composition of the Health Macro-Region of Cariri and the Health Region of Brejo Santo, Ceará state, Brazil (2012).

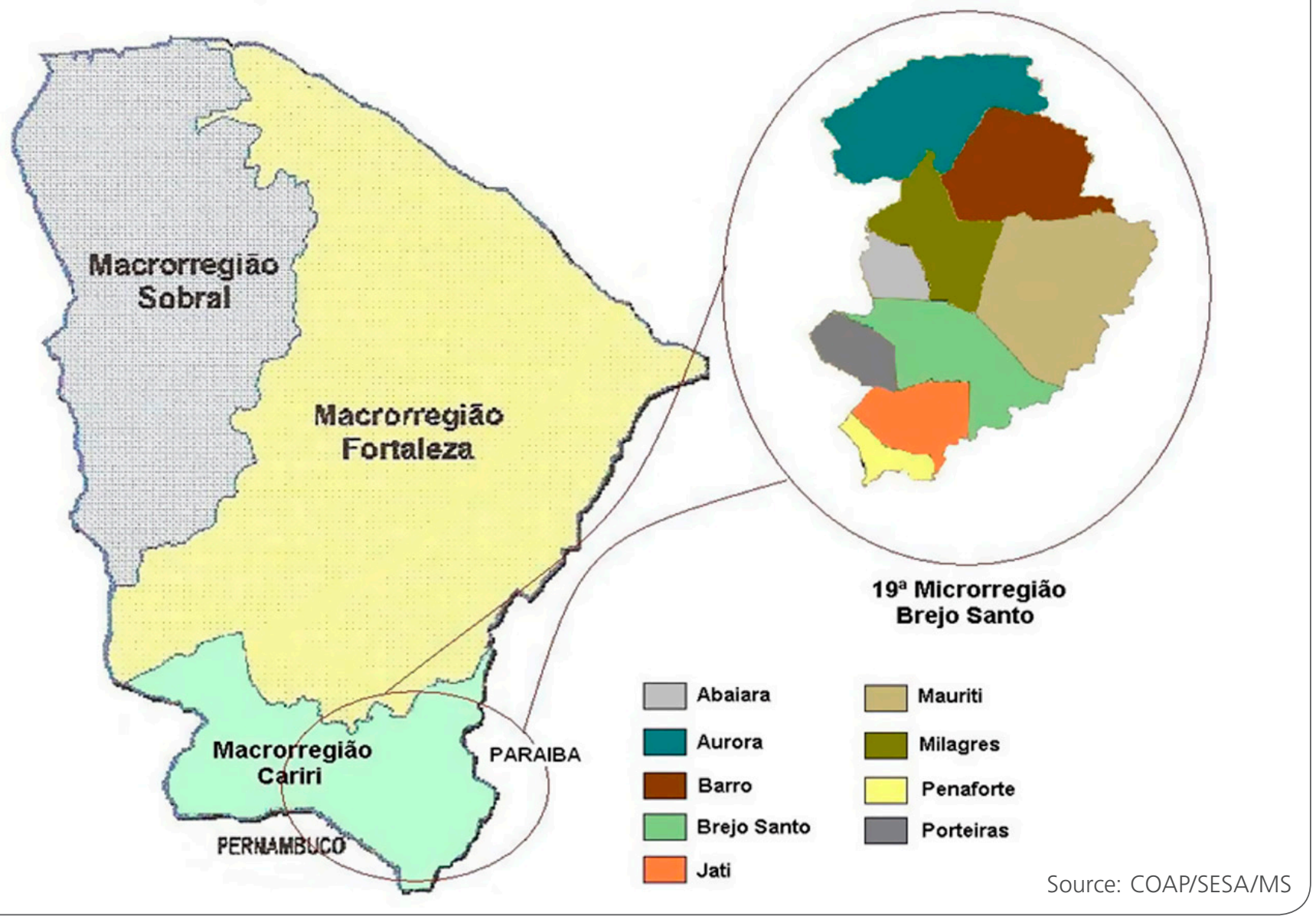


The population of the 9 municipalities that form the $19^{\text {th }}$ Health Region of Brejo Santo is 205,272 people. Brejo Santo is the municipality that stands out the most given its central position and regional influence on social and economic aspects. It is also the most populous municipality of the region, with 45,190 people [13].

Dengue control actions have been decentralized for the municipalities since 2000. However, within this regionalization context, monitoring, evaluation, planning and capacitating actions are regionally taken through the Regional Healthcare Coordination (CRES).

The amount of dengue fever outbreaks in most of the municipalities that compose the $19^{\text {th }}$ Health Region of Brejo Santo showed the need for not only further investigation on the subject but also for the pursuit for researchers and experts in dealing with epidemics. In this current study, action was the word of choice, constantly surrounded by verbs like notify, investigate, confirm, control, prevent, assist and promote in an attempt to win the war against dengue fever.

The situation here presented, as well as the lack of studies on the region, caused a certain uneasiness in this group of researchers in relation to the temporal trends of dengue fever. On account of that, the aim of this study was to characterize the temporal trends of dengue fever in the municipalities of the $19^{\text {th }}$ Health Region of Brejo Santo over the period between 2007 and 2013.

\section{Methods}

This is an observational, cross-sectional, descriptive study with a quantitative approach.

Data were supplied by the Information System for Notifiable Diseases (SINAN) and the Mortality Information System (SIM). SINAN is responsible for the registration and data processing of all notifiable diseases all over the country. It supplies information for analysis of morbidity profiles thus assisting the municipal, state and federal decision-making process. SIM, on the other hand, is in charge of collecting data on mortality in the country. It has many variables that allow for, according to the alleged cause of death, the creation of indicators and epidemiological investigation processes that will contribute to the effectiveness of health management.

The study was conducted in the $19^{\text {th }}$ Health Region of Brejo Santo over the period between January and December 2013. Data were collected from the local $19^{\text {th }}$ CRES and from the Brejo Santo Health Secretary.

The study included all notifications of dengue fever, dengue with complications and dengue hemorrhagic fever cases among all age groups which occurred in the municipalities of the $19^{\text {th }}$ Health Region of Brejo Santo between January 2007 and December 2013.

Data were extracted from the websites SINAM NET, SINAM ON LINE and SIM according to the available reports with the following variables: municipality, region, sex, age, year of notification, dengue classification, and death by dengue.

A completion form was used for secondary data, which were supplied by SINAM and SIM. The study was approved by the Ethics and Research Committee of the $A B C$ Medical School (FMABC) in Santo André/SP/Brazil, under the number 224.243, on March 03, 2013.

In order to describe the incidence and mortality rates in the studied region, the descriptive analysis of the data through relative and absolute frequencies was conducted. The statistical package used was Stata 11.0.

\section{Results and Discussion}

A total of 7,766 cases of dengue fever were confirmed in the period between 2007-2013, among which 5 evolved to death. The incidence in the region was of 378.1 cases per 10,000 inhabitants, and in the municipalities it ranged from $43.8 \mathrm{ca}-$ 
Table 1. Municipality-by-municipality description of epidemiological data of dengue fever in the $19^{\text {th }}$ Health Region of Brejo Santo from 2007 to 2013.

\begin{tabular}{|l|c|c|c|c|c|}
\hline \multicolumn{1}{|c|}{ Municipality } & $\begin{array}{c}\text { Average } \\
\text { Population }\end{array}$ & Number of Cases & $\begin{array}{c}\text { Incidence } \\
(\mathbf{x} 10,000)\end{array}$ & Number of Deaths & $\begin{array}{c}\text { Mortality } \\
(\mathbf{x} 100,000)\end{array}$ \\
\hline Abaiara & 10,539 & 448 & 425.1 & 1 & 9.5 \\
\hline Aurora & 24,906 & 109 & 43.8 & 0 & 0 \\
\hline Barro & 21,503 & 785 & 365.1 & 0 & 0 \\
\hline Brejo Santo & 44,166 & 3073 & 695.8 & 2 & 4.5 \\
\hline Jati & 7,625 & 273 & 358.0 & 0 & 0 \\
\hline Mauriti & 44,554 & 1380 & 309.7 & 0 & 0 \\
\hline Milagres & 28,692 & 576 & 200.8 & 0 & 0 \\
\hline Penaforte & 8,206 & 159 & 193.8 & 0 & 0 \\
\hline Porteiras & 15,219 & 963 & 632.8 & 2 & 13.1 \\
\hline 19th Region & 205,412 & 7,766 & 378.1 & 5 & 2.4 \\
\hline
\end{tabular}

ses/10,000 inhabitants to 695.8 cases/10,000 inhabitants (Table 1).

A high incidence in most of the municipalities of the Health Region of Brejo Santo can be observed. Aurora had the lowest incidence rate, with no epidemic or death records. On the other hand, Brejo Santo, the largest and most populous municipality, had the highest incidence, with 2 deaths and epidemic outbreaks in 2007, 2010 and 2013 on record. Porteiras, with a population of 15,219 people, also stands out due to the high incidence and two deaths and epidemic outbreaks in 2007 and 2010 on record. The other municipalities, with the exception of Penaforte, also notified outbreaks: Abaiara in 2007; Barro in 2011; Jati in 2010; Mauriti in 2010, 2011 and 2013; Milagres in 2011.

In 2010 the Ministry of Health created a new tool to evaluate the risk of dengue fever epidemics in the Brazilian states and municipalities over the period between 2010 and 2012. The tool makes use of five basic criteria, namely three from the healthcare sector, one from the environmental sector and the other from the demographic sector. Among the nine municipalities of the $19^{\text {th }}$ Health Region, four were classified as of moderate risk (Jati, Mau- riti, Milagres and Porteiras) and two as of high risk (Barro and Brejo Santo). Epidemic outbreaks were reported in all six municipalities over the period between 2010 and 2013 according to the information supplied above [14].

Regarding the incidence in the studied region, the annual rates of detection of dengue fever new cases/10,000 inhabitants were as follows: 155.5 in 2007, 9.5 in 2008, 2.2 in 2009, 69 in 2010, 54 in 2011, 29.6 in 2012 and 56.8 in 2013. As can be observed, there was an instability in rates year after year. (Figure 2).

Figure 2: Annual dengue fever incidence in the 19th Health Region of Brejo Santo over the period between 2007 and 2013.

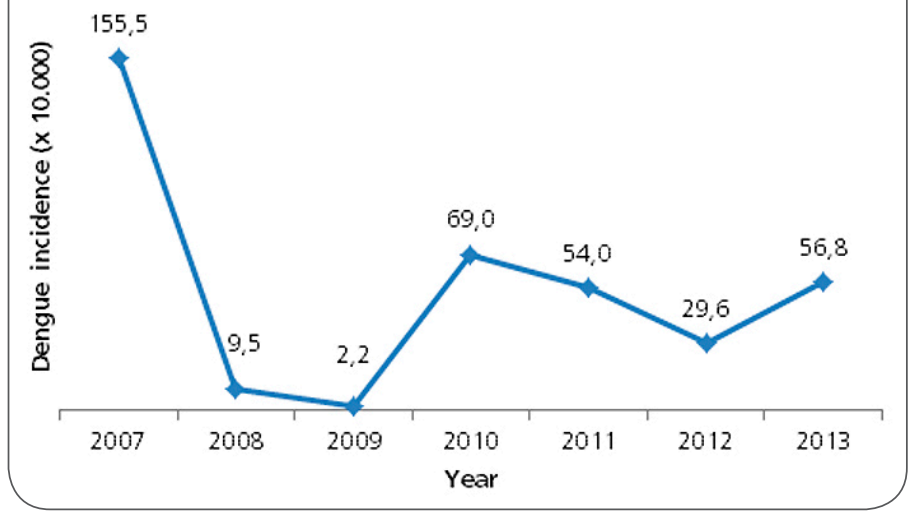


As seen in the chart above, there was a decrease in incidence between 2008 and 2009, followed by an increase from 2010 to 2013 with fluctuations in 2011 and 2012. In 2007 a great epidemic outbreak was reported in three municipalities, and Brejo Santo was at the top of the list with the highest number of notified cases and $68 \%$ of confirmed events. During the 2007 outbreak, a virus isolation was performed, and only DEN-2 was detected. In the 2010 outbreak, DEN-1 was isolated in the epidemic area.

The 2008 epidemic outbreak in Ceará stands out given the highest number of confirmed severe cases. The $19^{\text {th }}$ Health Region recorded low incidence in that year probably because a great part of the population was immune to DEN-2, the same virus responsible for the outbreak in the area the year before, or the effectiveness of the actions taken to combat the vector, which were intensified after the 2007 epidemic [11].

A epidemiological study performed in Aracajú/ Sergipe (a northeast state in Brazil) corroborates the above hypothesis. It shows that there was a decrease in numbers of dengue fever cases after the 2002 and 2008 epidemics, and the conclusion was the same as that reached in the $19^{\text {th }}$ Health Region [15].

Another study conducted in Ribeirão Preto/São Paulo presents similar results, with sharp fluctuations in the disease indicators and decreased numbers of cases after epidemic outbreaks attributed to the same reasons mentioned above: immunity and actions against the vector. A peak in number of cases can be observed in the first semester of the year owing to the fact it is the rainy season in the region, with high temperatures and winds [16].

It is important to point out that the incidence rate of notified cases is not the same as the number of confirmed cases. This gap between notification and confirmation can especially be seen in 2010, a year when the rate of notified cases was 1.5 times higher than the number of cases confirmed in the region (Figure 3).

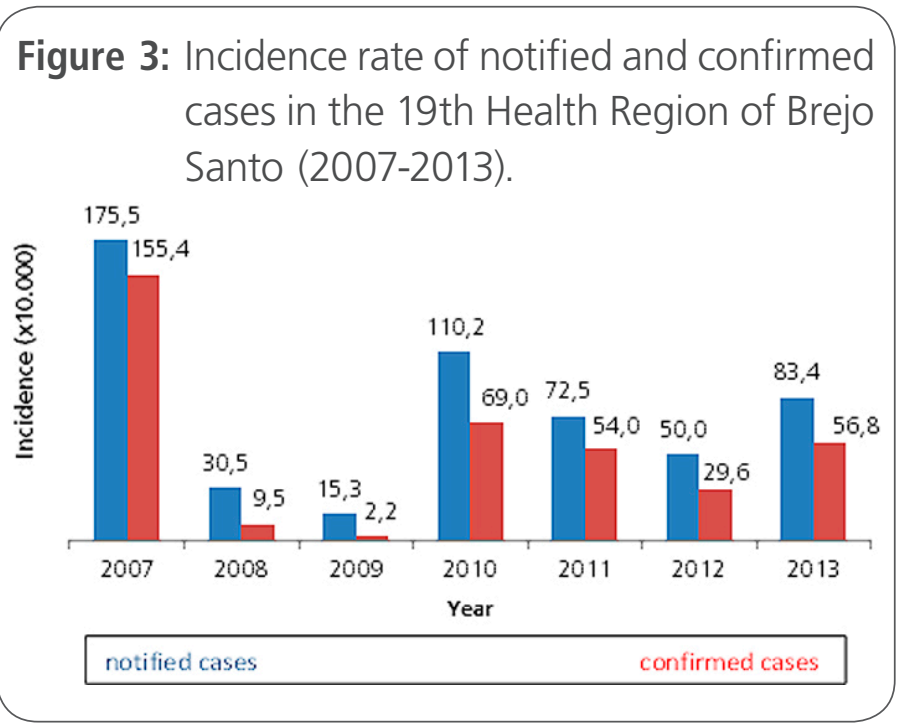

Silvano and Abreu [5] conducted a study on epidemiological connections in Lusophone countries. Brazil takes the leadership in dengue fever risk and number of cases. It ranks fifth among the countries that export dengue cases to Europe, and it is the Lusophone country with the largest number of outbreaks and where the disease has longer been classified as endemic. However, despite the fact no evidence of possible outbreak connections among countries was detected, this connection hypothesis should not be overlooked.

Data supplied by the Ministry of Health show that in 2013 the Northeast region in Brazil had the highest mortality rate by severe cases of dengue.

In spite of the high incidence, mortality rate by dengue fever in the Health Region of Brejo Santo varies, and during some years it goes down to $0 \%$. In 2007, this rate was as low as $0.97 / 100,000$ inhabitants. During 2008 and 2009, no deaths by dengue were reported. In 2010 the rate went back to $0.97 / 100,000$ inhabitants. In 2011 the rate went down to $0 \%$ again, and in 2012 , it rose to $0.48 / 100,000$ inhabitants. No deaths were reported in the region in 2013 (Figure 4).

Notably, all deaths happened during the 2007 and 2012 outbreaks. However, the death cases of 2012 occurred in municipalities with low incidence and no records of outbreaks. 
Figure 4: Mortality rate by dengue fever in the 19th Health Region of Brejo Santo, from 2007 to 2013.

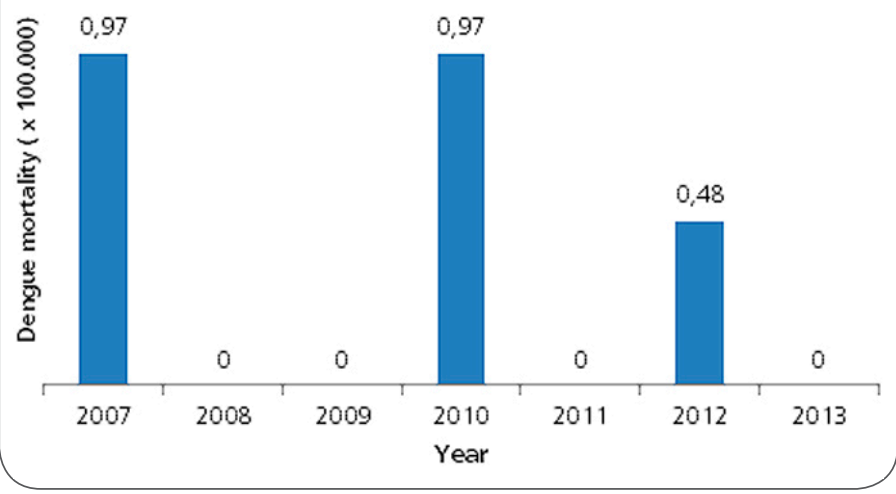

The disease has gradually become more lethal ever since the first deaths by dengue fever were reported. In 2007 dengue lethality rate was of 0.06\%; in 2010 it was of $0.14 \%$; in 2012, 0.16\% (Figure 5).

Figure 5: Annual dengue lethality rate in the $19^{\text {th }}$ Health Region of Brejo Santo -2007 to 2013.

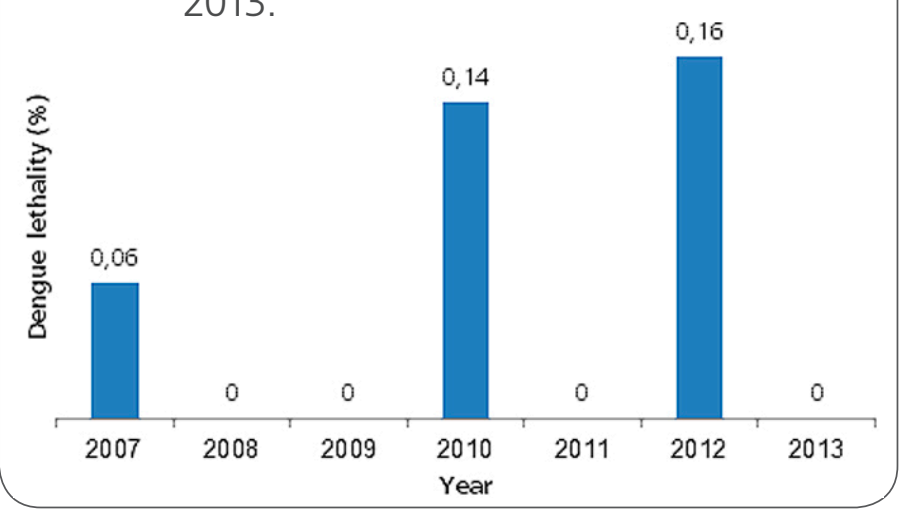

In a study on deaths by dengue in two Northeast municipalities the authors conclude that what seems to directly influence the occurrence of death is the clinical management of the cases. From what could be observed, when it comes to providing assistance to patients, the expected standard level of care was not reached in any of the evaluated services and the guidelines for the management of dengue fever is not being followed [17].

A study on the determining factors for death by severe dengue fever in Brazil shows that patients over 50 years of age suffering from severe den- gue fever were more likely to die than those below 14 years of age. The high death rate among aged adults could also be observed during dengue outbreaks in Puerto Rico and Taiwan, a fact probably caused by comorbidities which are more prevalent in this age group [18].

Hierarchical regression analyses show that male patients are more likely to die of dengue infection than female patients. In Brazil men tend to search for health assistance less frequently and later than women usually do, which causes a delay in the proper diagnosis and therapeutic approach in dengue cases. This hypothesis not only complies with the number of deaths among the male population, higher than in the female, but also emphasizes a biological and behavioral explanation. There is still a close relationship between ethnicity and socioeconomic status. Therefore, this association with deaths by severe dengue fever suggests that the barrier to the access to qualified healthcare services is stronger than the biological differences [18].

Over the last 10 years Brazil has reported a constant rise in number of hospital admissions for severe dengue cases. However, there has been a reduction in the dengue mortality rate comparing with the year 2010. These results can be partially explained by the change in the disease pattern, characterized by hyperendemic outbreaks, the simultaneous circulation of the four dengue serotypes and the lack of professional skills [18].

Ideally, Dengue Hemorrhagic Fever lethality rate should be lower than $1 \%$. Nevertheless, it may peak to $20 \%$ if not quickly diagnosed and properly treated $[3,14]$. In Brazil, the lethality rate of DHF has been above $5 \%$ over the past few years [19].

The standardization of the classification of dengue cases allows for the comparison of the epidemiological scenario between different regions. In general, it is classified after the clinical outcome, often retrospectively, and clinical and laboratory information must be provided. Those cases notified as suspected dengue fever remain on the system 
for 60 days so thatclassification can be made (case closing) [7].

Regarding the classification of dengue fever in the Health Region of Brejo Santo during the period this study was conducted, the most frequent form of infection found in the area was the Classic Dengue type (69.5\% of the cases), followed by the subtypes classified as disregarded (26.29\%), inconclusive (3.41\%) and other subtypes like Dengue Fever with Complications, ignored or in blank and Dengue Shock Syndrome (DSS) (0.62\%) (Figure 6). Disregarded cases were those with negative serology for dengue fever.

The 5 dengue deaths that occurred between 2007 and 2013 were classified as Dengue with Complications (3), Dengue Shock Syndrome (1) and Dengue Hemorrhagic Fever (1) (Table 2).
Figure 6: Dengue classification in the 19th Heath Region of Brejo Santo over the period between 2007 and 2013.

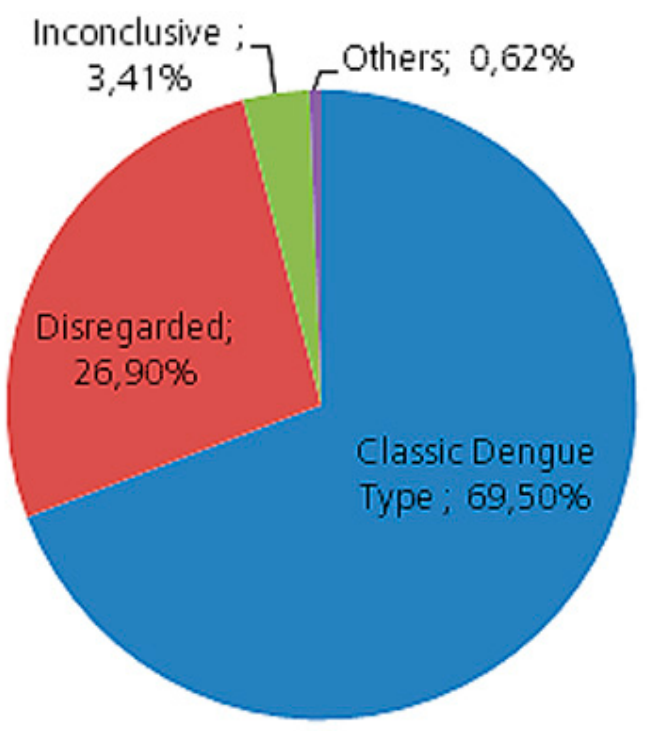

Table 2. Description of dengue deaths in the 19th Health Region of Brejo Santo, 2007-2013 period.

\begin{tabular}{|l|c|c|c|c|c|c|}
\hline \multicolumn{1}{|c|}{ Year } & Municipality & Date & Sex & Age & Area & Classification \\
\hline 2007 & Brejo santo & Jan 01,07 & Female & 43 years & Urban & DWC \\
\hline 2009 & Porteiras & Apr 04,07 & Male & 44 years & Urban & DSS \\
\hline 2010 & - & - & - & - & - & - \\
\hline \multirow{2}{*}{2011} & - & - & - & - & - & - \\
& Abaiara & Jun 02, 10 & Male & 7 months & Urban & DWC \\
\hline
\end{tabular}

2013

\section{Conclusions}

Dengue fever is a complex and recurrent issue in the Northeast region of Brazil, especially in the state of Ceará. An alarming number of cases $(7,766)$ were confirmed, with a higher incidence in most of the municipalities of the $19^{\text {th }}$ Health Region of Brejo Santo, over the period between 2007 and 2013. A fluctuation in incidence could be observed with interspersing periods of large epidemic outbreaks. A total of 6 out of the 9 municipalities that compose the region are at risk of dengue fever outbreaks.
According to the data supplied, the greatest challenge lies in controlling the disease and avoiding deaths in the Health Region. In order to achieve good results, it is necessary to involve people in the process of co-responsibility, to strengthen links with other sectors of society, to promote adequate and timely assistance to the population and to improve the flow of health information, thus generating proactive and effective actions.

Deaths by dengue fever are considered avoidable and they represent a frailty indicator in the health- 
care system. Some studies show the need to qualify the health assistance supplied through the use of the risk classification protocol, staging and evaluation of individuals with dengue fever. Four out five deaths occurred during epidemic outbreaks, and most of the deceased patients were adults.

In view of what has been here exposed, the high risk of outbreaks and the intense virus circulation, it is paramount to review the current actions taken against the disease, including health management spheres and assisting the general population in an attempt to reduce transmission and mortality rates.

\section{References}

1. Rouquayrol MZ, Filho NA. Epidemiologia \& Saúde. $6^{a}$ ed. Rio de janeiro: MEDSI; 2003.

2. Brasil. Programa Nacional de Controle da Dengue. Brasília (DF): FUNASA; 2002

3. Teixeira MG, Barreto MI, Guerra Z. Epidemiologia e medidas de prevenção do dengue. Inf Epidemiológico SUS 1999; 8: 05-33.

4. Braga IA, Valle D. Aedes aegypti: histórico do controle no Brasil. Ver epidemiologia e Serviços de Saúde 2007; 16(2): 113-118.

5. Silvano J, Abreu C. Dengue Fever in Portuguese Speaking Countries: Which Epidemiological Links May We Set? Acta Med Port 2014; Jul-Aug; 27(4): 503-510.

6. Tauil PL. Aspectos críticos do controle da dengue no Brasil. Rev Saúde Pública 2002; 18(3): 867-871.

7. Brasil. DENGUE: diagnóstico e manejo clínico adulto e criança. 4 ed. Brasília (DF): Ministério da Saúde; 2011.

8. Brasil. NOTA TÉCNICA No 023/2007. Aumento de casos de Febre Hemorrágica da Dengue (FHD) em crianças. Brasília (DF): Ministério da Saúde; 2007.

9. Brasil. Nota Técnica n 122/2013. Nova classificação de casos de dengue. Brasília (DF): Ministério da Saúde; 2013.

10. Brasil. Epidemiologia e Serviços de Saúde. V 16 - n 2. Brasília (DF): Ministério da Saúde; 2007.

11. Ceará Informe Semanal da Dengue 2014. [documento na internet]. 2014 [citado em 5 de ago 2013]. Disponível em: http:// salasituacao.saude.ce.gov.br/index.php/menu-principal/dengue.

12. Brasil. Decreto $n^{\circ} 7.508$, de 28 de junho de 2011. Regulamentação da Lei n 8.080/90. Brasília (DF): Ministério da Saúde; 2011.

13. Brasil. Contrato Organizativo de Ação Pública. 19 Região de Saúde Brejo Santo. Brasília (DF): Ministério da Saúde; 2012.

14. Ceará. Informe Semanal da Dengue. Alerta risco dengue. Fortaleza (CE): Secretaria da Saúde; 2011.

15. Alves JA, Santos JR, de Mendonça EN, Abud AC, Nunes Mda S, Fakhouri R, Inagaki AD, Marchioro M, Antoniolli AR. Epidemiological aspects of dengue in Aracaju, State of Sergipe, Brazil. Rev Soc Bras Med Trop. 2011; Nov-Dec; 44(6): 670-3.
16. Hino P, dos Santos CC, dos Santos MO, da Cunha TN, dos Santos CB. Temporal evolution of dengue fever in Ribeirão Preto, São Paulo State, 1994-2003. Cien Saude Colet. 2010; Jan; 15(1): 233-8.

17. Figueiró AC, Hartz ZMA, Brito CAA, Siqueira Filha NT, Cazarin G, Samico I, Cesse EAP et al. Óbito por dengue como evento sentinela para avaliação da qualidade da assistência: estudo de caso em dois municípios da Região Nordeste, Brasil, 2008. Cad Saude Publica 2011; 27(12): 2373-2385.

18. Moraes GH, de Fátima Duarte E, Duarte EC. Determinants of mortality from severe dengue in Brazil: a population-based case-control study. Am J Trop Med Hyg. 2013 Apr; 88(4): 6706. doi: 10.4269/ajtmh.11-0774.

19. Viana DV, Ignotti $E$. The ocurrence of dengue and weather changes in Brazil: a systematic review. Rev Bras Epidemiol. 2013 Jun; 16(2): 240-56.

20 Brasil. Resolução n. 196/96 do Conselho Nacional de Saúde. Dispõe sobre as diretrizes e normas regulamentadoras de pesquisa envolvendo seres humanos [documento na internet]. 1996 [citado em 5 ago 2014]. Disponível em: http://conselho. saude.gov.br/web_comissoes/conep/aquivos/resolucoes/23_ out_versao_final_196_ENCEP2012.pdf.

\section{Comment on this article:}

\section{8 in $8+\mathbf{S} P$}

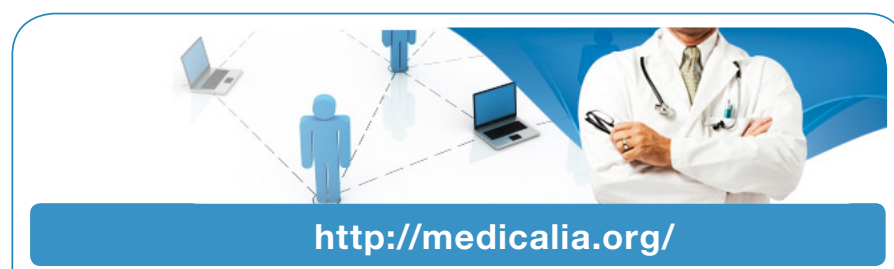

Where Doctors exchange clinical experiences, review their cases and share clinical knowledge. You can also access lots of medical publications for free. Join Now!

\section{Publish with iMedPub}

\section{http://www.imed.pub}

International Archives of Medicine is an open access journal publishing articles encompassing all aspects of medical science and clinical practice. IAM is considered a megajournal with independent sections on all areas of medicine. IAM is a really international journal with authors and board members from all around the world. The journal is widely indexed and classified Q1 in category Medicine. 